\title{
SINERGITAS PEMBANGUNAN EKONOMI LOKAL DAN PARIWISATA MELALUI PERATURAN DAERAH TERINTEGRASI
}

\section{LOCAL ECONOMIC AND TOURISM DEVELOPMENT SINERGIES THROUGH INTEGRATED REGIONAL REGULATIONS}

\author{
Danu Suryani dan \\ Warizal
}

\author{
Program Studi Hukum, Fakultas Hukum, \\ Universitas Djuanda Bogor. \\ Korespondensi : Danu Suryani, Tel. 087884266000 \\ e-mail : danu.suryani@unida.ac.id
}

Jurnal Living Law, Vol. 11, No. 2, 2019

hlm. 152159

\begin{abstract}
The high tourism visit is a potential that can be utilized to encourage local economic progress, this can be done on condition that the increase in tourism visits must be followed by an increase in the ability of the government and local communities to be able to synergize the tourism potential and the local economy because if not, an increase in tourism visits only adds benefits for tourism business activists who are not local residents so that local residents receive more negative impacts than positive impacts from increased tourism visits. This must be addressed, one of which is the synergy of the tourism potential management program with the local economic program in the local government.
\end{abstract}

Keywords : Synergy, Local Economy and Tourism, Regulation.

\begin{abstract}
Abstrak : Tingginya kunjungan pariwisata menjadi potensi yang dapat dimanfaatkan untuk mendorong kemajuan ekonomi lokal, hal ini bisa dilakukan dengan syarat bahwa peningkatan kunjungan wisata harus di barengi dengan peningkatan kemampuan pemerintah dan masyarakat lokal untuk dapat mensinergikan potensi pariwisata dan ekonomi lokal karena jika tidak, peningkatan kunjungan wisata hanya menambah keuntungan bagi para penggiat usaha pariwisata yang bukan warga masyarakat lokal sehingga warga lokal lebih banyak menerima dampak negative daripada dampak positif dari peningkatan kunjungan pariwisata. Hal ini harus disikapi, salah satunya dengan sinergisitas program pengelolaan potensi pariwisata dengan program ekonomi lokal yang ada di pemerintah daerah.
\end{abstract}

Kata Kunci : Sinergitas, Ekonomi dan Pariwisata Lokal, Perda.

\section{PENDAHULUAN}

Indonesia merupakan Negara dengan potensi pariwisata yang tergolong baik, hamper di setiap daerah memiliki potensi wisata, salah satunya di Kabupaten Bogor, saat ini di Kabupaten Bogor telah dibentuk BUMD Pariwisata yaitu PT Sayaga Wisata. Sesuai dengan UU/No.5/1962 mengenai Perusahaan Daerah dasar awal untuk pendirian BUMD. Hakikat pendirian BUMD sebagai prangkat atau kelengkapan bagi pemerintah daerah dalam membangun perekonomian wilayahnya.

Pendirian BUMD juga didasari karena keterbatasan dari ruang gerak Perangkat
Daerah untuk menjalankan semua misi, dalam melakukan usaha. Oleh karenanya BUMD didirikan dengan 5 (lima) tujuan utama, yaitu memupuk keuntungan (profit oriented), peningkatan pelayanan publik, pioneering atau perintis bisnis yang tidak berani dimasuki swasta, prime mover ekonomi daerah yang umum bergerak pada industri di hulu, membantu golongan ekonomi lemah. Hal tersebut sama dengan konsep pendirian Badan Usaha Milik Negara (BUMN), tujuan dari pendirian BUMD melekat dengan tugasnya sebagai agent of development, hal ini juga yang membedakannya dengan perusahaan 
swasta. Maka BUMD tentunya memerlukan kententuan untuk mengatur regulasi yang secara jelas menjamin pengelolaan berjalan dengan profesional.

Badan Usaha Milik Daerah (BUMD) berperan penting guna mendorong meningkatnya perekonomian nasional. mendorong percepatan juga pemerataan dalam pembangunan ekonomi pada tingkat daerah. Selain itu Berdirinya BUMD seharusnya dapat memberikan multiplier effectyang bagi kemajuan masyarakat. Salah satu BUMD yang di Kabupaten Bogor adalah PT Sayaga Wisata.

PT Sayaga wisata merupakan perusahaan Daerah yang dibangun dengan misi Menjadi Pemilik dan Pengelola bisnis wisata dan sarana wisata yang terkemuka dan berkontribusi besar pada pendapatan asli daerah dan pemberdayaan masyarakat sekitar. Adapun misinya adalah memiliki unit usaha yang profitable, enjadikan Objek wisata pemerintah Bogor menjadi tempat tujuan wisata yang berkelas, dikelola secara profesional dan memberi manfaat ekonomi bagi pemerintah daerah dan masyarakat sekitar, membangun proses bisnis yang memiliki effektivitas, effesiensi dan daya saing yang tinggi.

Secara filosofis, meskipun sebagai badan usaha, pembentukan BUMD tentunya tidak hanya didirikan dengan tujuan keuntungan materi, akan tetapi juga juga membawa peran atau fungsi pelayanan yang merupakan kewajiban pemerintah kepada masyarakat setempat. Mengingat keterkaitan atau hubungan yang dapat disinergikan anatara pariwisata dengan pengembangan ekonomi lokal. Dimana potensi wisata mempunyai corak yang sama dengan potensi ekonomi lokal namun akan cederung berbeda dengan potensi wisata dan ekonomi lokal di daerah lain. Oleh karena itu tentunya cukup beralasan bila kita berkesimpulan bahwa bisa dilakukan akselerasi pembangunan ekonomi lokal melalui pengembangan pariwisata atau sebaliknya akselerasi pembangunan pariwisata melalui pengembangan ekonomi lokal. Oleh sebab itu maka dirasa perlu untuk memberikan tambahan peran pada PT Sayaga Wisata untuk dapat mengembangkan Potensi Wisata di Kabupaten Bogor yang sekaligus dapat meningkatkan ekonomi lokal. Hal ini juga mempertimbangkan dari 10 pelaku usaha atau penggiat usaha pariwisata lebih dari 60\%nya bukanlah masyarakat local, dimana kebanyakan masyarakat lokal saat ini hanya berperan sebagai pekerja pada level terendah dalam pengmbangan wisata dan ekonomi lokal. Hal tersebut bisa dilihat dari kondisi saat inidi objek wisata di jalur puncak Bogor sebagai salah satu objek wisata faporit di Kabupaten.

Sebagaimana dikemukakan sebelumnya, sama halnya seperti potensi ekonomi lokal, potensi pariwisata secara umum akan sangat berbeda antara satu daerahdengan daerah lainnya, akan tetapi potensi ekonomi lokal dan potensi pariwisata merupakan dua hal yang dapat dijalankan beriringan atau bersamaan. Oleh karenanya perencanaan pembangunan pariwisata suatu daerah perlu diawali dengan mengenali dan mempertimbangkan karakter ekonomi daerah, atau sebaliknya. Lebih dari itu tentu dari sisi eksternal termasuk harus dipertimbangkan juga interaksinya dan kondisi dengan daerah lain disekitarnya. Dengan demikian strategi pembangunan pariwisata yang baik adalah yang sekaligus mengembangkan ekonomi daerah. Hal tersebut sesuai dengan pandangan bahwa ekowisata bisa berperan sentral dalam melakukan konservasi dan pembangunan pedesaan (Nelson dalam Bambang, 2016). Menurut Afifi bahwa mengaitkan pembangunan ekonomi lokal sebagai sebuah strategi dalam pengentasan kemiskinan, dan masyarakat miskin merupakan aset yang kemudian berpotensi menjadi sebuah kekuatan besar untuk memacu perkembangan ekonomi di daerah (Indah Martati dkk, 2013).

Keinginan kuat pemerintah daerah untuk menyusun strategi pengembangan pariwisata yang berbasis pada ekonomi lokal akanmenjadi kunci yang akan menarik partisipasi masyarakat local, 
dengan demikian adanya pembangunan pariwisata yang berbasis pada ekonomi local ini selain akan memberikan manfaat langsung bagi PAD melalui BUMD, lebih dari itu akan membangun ekonomi masyarakat di daerah setempat sehingga keuntungan berikutnya adalah pembayar pajak di daerah dan penanam modal juga meningkat. Keberhasilan itu tentunya harus diawali oleh kekuatan yang berupa kebijakan pemerintah yang mendukung.

Selain adanya BUMD pariwisata, Pemerintah Daerah juga membentuk Dinas Kebudayaan dan Pariwisata yang merupakan perangkat daerah sebagai unsur pendukung penyelenggaraan pemerintah daerah, dibentuk Berdasarkan Peraturan Daerah Peraturan Daerah Nomor 12/ 2016 mengenai Pembentukan dan Susunan Perangkat Daerah. Adapun tugas dan fungsinya adalah membantu Kepala Daerah dalam melaksanakan urusan kebudayaan dan pariwisata termasuk dalam perumusan kebijakan, pemasaran pariwisata, kemitraan, sumber daya manusia dan ekonomi kreatif juga kebudayaan. Selain itu juga sebagai pelaksana monitoring, evaluasi, dan pelaporan di bidang destinasi pariwisata, pemasaran pariwisata, kemitraan, sumber daya manusia dan ekonomi kreatif serta kebudayaan. Adanya dinas ini juga belum optimal bersinergi dengan BUMD Pariwisata dan juga dengan Dinas terkait lain yang mengelola ekonomi lokal.

Atas dasar berbagai permasalahan tersebut, kami sebagai akademisi merasa tertarik melakukan kajian mengenai "Sinergi Pembangunan Ekonomi Lokal dengan Pembangunan Pariwisata melalui Peraturan Daerah".

\section{METODE PENELITIAN}

Sebagai usaha pendekatan pencarian dan penyajian data, metode yang digunakan dalam penelitian ini, yaitu sebagai berikut: Kajian Yuridis Normatif yang juga disebut penelitian doktrinal menerjemahkan hukum sebagai apa yang tertulis dalam peraturan perundang- undangan (law in books) atau hukum dikonsepkan sebagai kaidah/norma yang merupakan patokan berperilaku yang dianggap pantas. Sehubungan dengan hal tersebut, maka sumber datanya hanyalah data sekunder, yang terdiri dari Bahan hukum primer atau bahan hukum yang mengikat yaitu Peraturan Perundangundangan. Peraturan perundang-undangan yang berkaitan dengan objek penelitian, Bahan Hukum Sekunder sebagai penjelasan bahan hukum primer, seperti rancangan undang-undang, hasil-hasil penelitian, atau pendapat pakar hukum, dan lainnya yang terkait dengan objek penelitian dan Bahan Hukum Tersier, atau bahan yang memberikan petunjuk maupun penjelasan terhadap bahan hukum primer dan bahan hukum sekunder, seperti kamus (hukum), ensiklopedia, artikel-artikel pada koran/surat kabar dan masalah-masalah yang terkait dengan objek penelitian.

Selain itu dilakukan juga Kajian Yuridis Sosiologis, hukum dikonsepkan sebagai pranata sosial secara riil dikaitkan dengan variabel sosial lain. (Amiruddin dan Zainal Asikin, 2003).

Terakhir sebagai penyempurna konsep yang akan ditawarkan dari kajian ini, maka dilakukan juga Kajian Yuridis Komparasi, jika ditemukan ada persamaan dari masing-masing sistem hukum tersebut, dapat dijadikan dasar unifikasi sistem hukum. Dalam kaitannya dengan kajian hukum pada penelitian ini, maka diperlukan komparasi atau perbandingan dari berbagai daerah yang sudah terlebih dahulu atau dinilai sukses dalam pengelolaan Badan Usaha Milik Daerah khususnya terkait pasar tradisional. Hal tersebut tentunya dengan pertimbangan seperti kondisi yang sesuai dengan Kabupaten Bogor, maka tidak ada salahnya diterapkan atau menjadi bahan pertimbangan bagi penyusunan peraturan daerah di Kabupaten Bogor.

\section{PEMBAHASAN}

\section{A. MENGENAL POTENSI PARIWISATA DAN EKONOMI DAERAH}


Bogor merupakan daerah penyanggah Ibu Kota Negara dengan jarak sekitar 60 kilometer dan waktu tempuh menggunakan jalur atau jalan tol Jagorawi dengan kendaraan mobil kurang lebih sekitar 1 - 1,5 jam dalam kondisi lalu lintas lancar. Bias juga ditempuh dengan menggunakan kereta listrik commuter line yang hanya memerlukan waktu tempuh 1 jam sampai dari Jakarta. Dalam kesempatan ini kita akan uraikan bagaimana potensi pariwisata dan Ekonomi Lokal di Kabupaten Bogor:

1. Potensi Pariwisata

Potensi pariwisata Kabupaten Bogor tentunya sangatlah potensial. Tidak kurang dari 26 objek alam seperti Pemandian Air Panas Ciseeng, Perkebunan Teh Cianten, Air Panas Ciseeng, Goa Gudawang, Air Panas Gunung Salak Endah, Wana Wisata Giri Jaya, Ekowisata Bodogol, Curug Cilember, Taman Safari Indonesia, Curug Ngumpet, Kawah Ratu, Perkemahan Gunung Bunder, Curug Cigamea, Taman Wisata Air Panas Gunung Pancar, Perkebunan Teh Gunung Mas, Panorama Alam Riung Gunung, Kawasan Puncak, Talaga Warna, Gunung Salak Endah, Curug Country, Curug Nangka, Curug Luhur Indah, Situ Gunung Putri, Situ Kadongdong, Situ Kemuning dan Situ Cikaret yang posisinya ada di wilayah perkantoran pemerintahan.

Selain itu, tidak kurang dari 35 objek budaya yang diantaranya: Situs Pemakaman Arca Domas, Plaza Budaya 2010 - Taman Wisata Mekarsari, Lingkung Seni Gentra Kaheman, Lingkung Seni Longkewang, Studio Seni Indonesia, Sanggar Seni Dharma Kerti Wisesa, Sanggar Seni Widaswara, Lingkung Seni Gentra Daya Mandiri, Lingkung Seni Giri Sunda Pura, Padepokan Galuh Pakuan, Padepokan Galuh Pakuan, Pura Parahyangan Agung Jagatkharta, Kampung Budaya Sindang Barang, Pencak Silat Cimande, Pencak Silat Putra Pajajaran, Lingkung
Seni Komara Group, Sanggar Seni Widaswara.

Melihat potensi wisata tersebut ternyata di Kabupaten Bogor tidak hanya ada Puncak Bogor Selatan, karena ada juga di Bogor Barat yang belum tersosialisasi dengan baik seperti di Tenjolaya, ada wisata Puncak, keindahan pegunungan, air terjun, arena permainan air akan memberikan kenyamanan pada wisatawan.

Untuk wilayah Bogor barat, sampai sejauh ini yang paling sering dikunjungi di Kecamatan Tenjolaya adalah Curug Ciputri dan Curug Luhur karena memiliki panorama alam indah dengan udara sejuk. Termasuk dapat juga menikmakti wisata budaya peradaban Islam dengan adanya situs arca menhir, domas, benda prasejarah di Leuwiliang, dan budaya peradaban Islam pertama yang ada di Kabupaten Bogor. Adanya potensi itu, maka saat ini telah dibentuk BUMD Pariwisata, Dinas kebudayaan dan pariwisata termasuk dinas-dinas lain yang terkait sebagai prangkat dan kelengkapan pemerintah Kabupaten Bogor dalam menjaga dan mengoptimalkan pariwisata yang ada.

2. Potensi Ekonomi Lokal

Melihat data Produk Daerah pada Usaha Mikro, Kecil dan Menengah di Kabupaten Bogor dalam klasifikasi Wilayah Kecamatan sebagai berikut:

- Nanggung Hasil perkebunan dan kehutanan

- Leuwiliang Bata Merah

- Leuwi Sadeng Pandai besi, bunga kering

- Pamijahan Perikanan (Udang Air Tawar)

- Cibungbulang Makanan, konveksi pakaian muslim, tas, jaket

- Ciampea Tas. Ikan patin

- Tenjolaya Pertanian dan perikanan

- Rumpin Split, Batu belah, Tras, Pasir, Telur ayam, Bambu 
- Cigudeg Hasil tambang (split, tras, andelit)

- Sukajaya Hasil hutan dan perkebunan

- Jasinga Golok dan alat pertanian

- Tenjo Dodol, Emping melinjo

- Parung Panjang Kopi, madu, tas

- Dramaga Sepatu Balita, Manisan, Replika pesawat

- Ciomas Sepatu dan Sandal

- Kemang Peternakan, kue basah\&kering, keset, sepatu, sandal

- Rancabungur Tanaman hias, lidah buaya

- Parung Konveksi, perikanan, pabrik tahu

- Ciseeng Perikanan (Ikan hias, lele, gurame), konveksi pakaian dalam

- Gunung Sindur Tanaman hias anggrek dan lidah buaya

- Tamansari Sepatu, Sandal, Tanaman hias

- Cijeruk Manisan pala, sirih instant, ayam ras, besek

- Cigombong Konveksi rajutan, aneka kripik

- Caringin Konveksi bordir

- Ciawi Sepatu, sepatu bola, boneka, makanan tradisional

- Cisarua Susu sapi, Rajutan

- Megamendung Kantong Kertas, Bilik Bambu, Bunga potong, Tanaman hias, aneka makan dari pisang, tas kantor

- Sukaraja Sagu Kasar, tapioka, perikanan lele, dendeng lele

- Babakan Madang Kue semprong, warung makanan, makanan ringan

- Citeureup Kerajinan logam (crom), accessories mobil, alat-alat rumah tangga, Alat-alat/ kebutuhan rumah sakit

- Cibinong Makanan ringan (keripik singkong), kerajinan tangan

- Bojong Gede Konveksi pakaian dalam, dodol

- Tajur Halang Buah-buahan

- Sukamakmur Aci singkong, meubelair, anyaman bilik
- Cariu Sepatu dan sandal, makanan (sirup madu)

- Tanjungsari Tas

- Jonggol Makanan ( kacang garing, roti, keripik, tahu, opak)

- Cileungsi Jahe, ginseng, kopi instant; minuman sari buah

- Klapanunggal Hasil tambang (split, tras, andelit), makanan, konveksi

- Gunung Putri Kue kering

Potensi di atas tentunya banyak yang bisa disinergikan dengan pengembangan pariwisata.

\section{B. SINERGITAS PEMBANGUNAN PARIWISATA DAN EKONOMI LOKAL}

Dengan adanya otonomi daerah, maka tingkat kemandirian dan kemampuan masing-masing wilayah di Indonesia akan sangat menentukan arah dan kualitas pembangunan di masing-masing daerah. Salah satu yang jadi perhatian penting selain peningkatan kualitas sumber daya manusia atau dalam indikator pendidikan. Pada bidang ekonomi juga menjadi objek yang juga harus diperhatikan. Melihat kondisi saat ini, diperlukan solusi baik dalam jangka pendek ataupun solusi dalam jangka panjang khususnya dalam menghadapi isu-isu atau permasalahan ekonomi pada daerah termasuk harus ada kritisasi pada kebijakan yang belum tepat pada saat ini. Selain itu pada bagian awal diperlukan komitmen dari Pemerintah daerah mulai dari mengenal potensi daerah yang harus dikembangkan, penyusunan kebijakan, pelaksanaan kebijakan hingga pengawsan dan evaluasi dari program yang telah dijalankan.

Secara teoretis, untuk menjadikan suatu kawasan sebagai objek wisata yang baik ada beberapa hal yang perlu yaitu: Faktor kelangkaan, Faktor kealamiahan, Faktor pemberdayaan masyarakat, Faktor Keunikan, Faktor optimalisasi lahan, Faktor pemerataan. Dengan itu diharapkan tercipta kondisi nyaman, masyarakat lokal tirtib sehingga menjadi utuh dan padu 
antara masyarakat lokal, pemerintah dan pengelola kawasan wisata (Utama, 2006).

Masih banyaknya kondisi pariwisata yang bersifat musiman menghasilakan pekerjaan juga bersifat musiman, akhirnya menghadirkan tingginya tingkat pengangguran dalam waktu tertentu. Hal berpengaruh pada ekonomi lokal yang rentan terhadap perputaran ekonomi. Ini yang harus dipikirkan oleh para penggiat pariwisata, termasuk pemerintah dan masyarakat. Hal lain yang tdak kalah penting adalah kedepan kemajuan sektor pariwisata harus memberikan dorongan bagi kemjuan ekonomi yang kuat pada wilayah setempat atau keberadaan pariwisata bisa menghasilkan pendapatan bagi ekonomi lokal. Atau dengan kalimat lain pariwisata saat ini tidak hanya dibebani peningkatan devisa tetapi juga langsung bagaimana pariwisata sebagai pendekatan ekonomi dengan turut serta mengentaskan kemiskinan (Wahyu Prihanta, dkk, 2017)

Adanya potensi ekonomi lokal yang banyak varian, harus di dorong agar pengembangan ekonomi wilayah tidak berbasis pada satu sektor usaha tertentu. Hal ini diperlukan guna menjaga stabilitas siklus usaha sehingga tetap menjaga lapangan pekerjaan disaat salah satunya ada pada posisi jenuh.

Hal yang harus tentunya juga diperhatikan dalam kemajuan pariwisata adalah adanya intraksi atau hubungan yang antara wisatawan dengan masyarakat lokal, yang secara langsung atau tidak langsung akan adanya akulturasi nilai kehidupan. Positifnya intraksi wisatawan dan masyarakat lokal akan memperluas pengetahuan masyarakat lokal tentunya selain melahirkan banyakpeluang memajukan atau pengembangan diri masyarakat lokal.hal lainnya yang bersifat positif adalah membangun sikap toleransi pergaulan yang menjadi sarana kuat dalam pembangunan bangsa. Bila dengan wisatawan asing, hubungan ini di samping menambah nilai pergaulan tentunya juga akan memperkuat nilai-nilai pribadi karena nilai pribadi asli warga lokal yang ramah merupakan daya tarik yang dihargai orang asing. Wisatawan Asing ingin yang lain dengan yang ada di negaranya atau ingin sesuatu yang asli (Spillane, 1987: 52).

Pengembangan pariwisata memiliki multiplier effect, oleh karenanya pemerintah harus mampu mendiversifikasi potensi wisata alam, kreatif, kuliner, termasuk olahraga. Sehingga manfaat yang diperoleh tidak hanya berupa pajak dan retribusi akan tetapi dapat dirasakan juga oleh masyarakat, lapangan kerja dan sektor UMKM atau peningkatan ekonomi lokal.

Pemerintah daerah, masyarakat dan pengusaha adalah tiga kelompok paling berpengaruh untuk menentukan keberhasilan sinergitas pariwisata dan ekonomi lokal. Pemerintah daerah, memiliki kekuatan dalam satu hal, namun terbatas dalam hal lainnya, demikian juga masyarakat lokal dan pengusaha. Sinergi antara ketiganya untuk merencanakan bagaimana ekonomi daerah dan pariwisata ini dikembangkan tentu harusmenjadi putusan bersama dan saling terkait.

Pemerintah daerah memiliki kewenangan dalam penyusunan peraturan, menyediakan berbagai sarana dan prasaran, melahirkan peluang, juga membentuk wawasan orang banyak, akan tetapi tidak banyak tau bagaimana proses kegiatan ekonomi berlangsung. Masyarakat lokal sebagai pihak yang juga harus terlibat memiliki peran menjaga kondisi social masyarkat agar tidak banyak terpengaruhi oleh dampak negative dari tingginya pariwisata. Termasuk dengan meningkatkan kemampuan dan peran diri dari dalam bersinergi dengan pengusaha untuk menggali kebutuhan wisatawan sehingga dapat memutar roda perekonomian lokal. Ada skema yang dapat dilakukan dalam sinergitas pembangunan ekonomi lokal melalui pengembangan pariwisata sebagai berikut: 


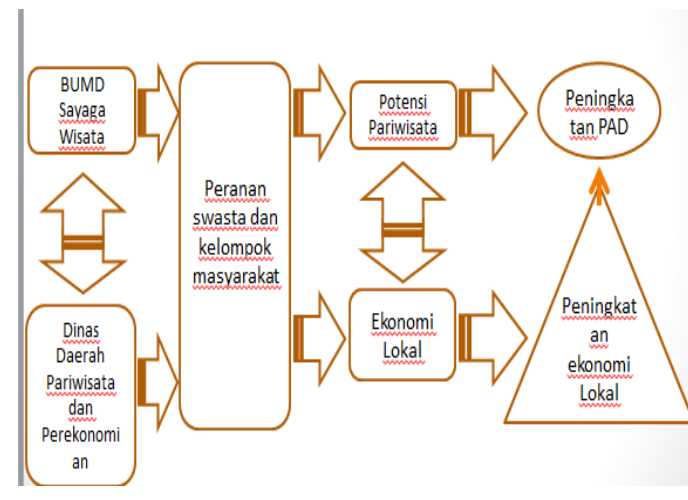

KESIMPULAN

Adanya potensi wisata seharusnya dapat dimanfaatkan sebagai pendorong ekonomi lokal, semakin meningkatnya kunjungan wisata harus di barengi dengan peningkatan kemampuan pemerintah dan masyarakat lokal. Jangan sampai peningkatan kunjungan wisata hanya menambah keuntungan bagi para penggiat usaha pariwisata yang bukan warga masyarakat lokal atau justru adalah para pengusaha asing yang memainkan investasinya di Kawasan Kabupaten Bogor sementara warga lokal hanya menjadi pegawai biasa yang jika harus berhitung, warga lokal lebih banyak merasakan dampak negatif daripada dampak positif dari adanya kemajuan kunjungan wisatawan ke Kabupaten Bogor.

Hal ini tentu harus disikapi, salah satunya dengan peningkatan peran pengelola pariwisata di Kabupaten Bogor yang saat ini dikelola oleh PT Sayaga Wisata, dan Dinas Pariwisata dan Kebudayaan Meskipun berbentuk Perseroan Terbatas, sebagai Badan Usaha Milik Daerah, PT Sayaga Wisata harus juga membawa misi pelayanan publik, maka tentunya tidak berlebih jika harus dimandatkan misi peningkatan ekonomi lokal selain pengelolaan dan peningkatan pariwisata di Kabupaten Bogor kepada PT Sayaga Wisata, hal tersebut harus didukung juga dengan peningkatan kordinasi antara SKPD dan BUMD yang ada. Untuk mewujudkan hal tersebut harus dibuat peraturan daerah yang terintegrasi antara pengembangan pariwisata dengan potensi ekonomi lokal.

\section{SARAN}

Pemerintah Daerah harus menyusun blue print yang tidak hanya menggambarkan harapan kemajuan pariwisata, akan tetapi harus juga menjelaskan pola sinegitas antara SKPD dan BUMD yang mengelola pariwisata dan Ekonomi lokal. Sehingga harapan kedepan kemajuan pariwisata tidak hanya membawa banyak dampak negatif pada masyatrakat lokal, akan tetapi dapat juga berdampak pada kemajuan ekonomi masyarakat lokal.

\section{DAFTAR PUSTAKA}

Utama, I Gusti Bagus Rai. 2006. “Konsep Pariwisata (Kajian Sosiologi dan Ekonomi)", dalam http://raiutama.blog.friendster.com/2006/09/konsep-pariwisata/

Mumuh Muhsin Z. 2010, Makalah Potensi Wisata Kabupaten Bogor, Universitas Padjadjaran, Jatinangor

Spillane, James.1985. Ekonomi Pariwisata, Sejarah dan Prospeknya.Yogyakarta: Kanisius.

Wahyu Prihanta, dkk, Pembentukan Kawasan Ekonomi Melalui Pengembangan Ekowisata Berbasis Masyarakat, Volume 14, Mei 2017, Issn 1693-3214, Hal. 73 http://ejournal.umm.ac.id/index.php/dedikasi/article/view/4304 
Johannes, 2003, Perbandingan Hukum Kontrak, Materi Kuliah Universitas Katolik Parahyangan, Program Pascasarjana, Program Studi Magister Ilmu Hukum.

Amiruddin dan Zainal Asikin, 2006, Pengantar Metode Penelitian Hukum, PT. Raja Grafindo Persada, Jakarta, hlm. 133-134.

Bambang, Supriadi. 2016, Pengembangan Ekowisata Pantai Sebagai Diversifikasi Mata Pencaharian. Vol. 18 No. 01. 2016. ISSN : 1410-7252. Hal. 3 http://jurnal.umer.ac.id/index.php/ipp/article/view/

Indah Martati, Suminto, Andi Syarifuddin. 2013, Model Penciptaan Lapangan Kerja Melalui Pengembangan Ekonomi Lokal Pada Kecamatan Samarinda Ilir. Vol. 15 NO 2 .ISSN: 1411-1438. Hal. 124 http://jurnalmanajemen.petra.ac.id/index.php/man/article/view/18772/18496 